\title{
A Polysynaptic Feedback Circuit in Rat Visual Cortex
}

\author{
Randall R. Johnson ${ }^{1,2}$ and Andreas Burkhalter ${ }^{1}$ \\ ${ }^{1}$ Department of Anatomy and Neurobiology, Washington University School of Medicine, St. Louis, Missouri 63110, and \\ 2Section of Neurosurgery, Yale University School of Medicine, New Haven, Connecticut 06520
}

\begin{abstract}
Feedback connections from extrastriate cortex to primary visual cortex (V1) in the primate may provide "top-down" information that plays a role in visual attention and object recognition. Our work in a rodent model of corticocortical circuitry demonstrates that feedback pathways synapse preferentially with pyramidal cells in V1 (Johnson and Burkhalter, 1996) and favor excitation over inhibition in cortical microcircuits (Shao and Burkhalter, 1996).

To investigate the polysynaptic circuits activated by feedback inputs, we studied chains of neurons postsynaptic to feedback connections using a combination of axonal tract tracing and anterograde degeneration. This approach enabled independent labeling of local collaterals of forward-projecting neurons in V1 and feedback connections from extrastriate lateromedial (LM) visual area to V1. Postsynaptic targets were identified in the electron microscope after retrograde transport of biotinylated dextran amine (BDA) to identify dendrites of forward-projecting
\end{abstract}

neurons (i.e., from V1 to LM) and postembedding immunogold labeling to identify GABAergic interneurons.

The results show that feedback connections provide strong monosynaptic input to forward-projecting neurons in V1. These neurons in turn make local connections that preferentially form synapses with other pyramidal cells ( $\sim 97 \%)$, many of which were identified as forward-projecting neurons. This indicates that feedback pathways provide input directly to neurons which make the reciprocal forward connection, and that feedbackrecipient forward-projecting neurons are strongly interconnected. The function of these excitatory networks within V1 may be to amplify feedback activity and provide a circuit for modulation of striate cortical activity by top-down influences.

Key words: corticocortical connections; feedback connections; intrinsic connections; visual cortex; electron microscopy; postembedding immunocytochemistry
Recent evidence from macaque monkey suggests that the cortical representation of a visual stimulus can be shaped by "top-down" influences involving attention and past experience (Desimone and Duncan, 1995; Maunsell, 1995). It has been proposed that these signals originate extraretinally in higher cortical areas and are sent via feedback connections to hierarchically lower areas (Motter, 1993). Modulation of visual responses by extraretinal information was first described in primate extrastriate visual cortex (Haenny et al., 1988; Moran and Desimone, 1985; Maunsell et al., 1991), but more recently has also been demonstrated in primary visual cortex (V1) (Motter, 1993; Press et al., 1994). The purpose of corticocortical feedback in the monkey, similar to corticogeniculate feedback in the cat (Sherman and Koch, 1986; Sillito et al., 1994), may be to alter the responsiveness of forwardprojecting neurons, thereby modulating the transfer of information to higher areas. However, the cortical circuits that underlie this modulation are presently unknown.

We have used the rodent visual cortex as a model system for examining synaptic connectivity in pathways that link visual cortical areas. Although the laminar pattern of forward and feedback terminations differs slightly between rat, cat, and monkey (Coogan and Burkhalter, 1993), basic principles of organization are

\footnotetext{
Received April 21, 1997; revised June 5, 1997; accepted July 2, 1997.

This work was supported by R01 Grant EY05935 from the National Eye Institute (A.B.) and a postdoctoral fellowship from the James S. McDonnell Center for Higher Brain Function (R.R.J.). We thank Tom Woolsey, Joel Price, Jeanne Nerbonne, Jim Huettner, and David Van Essen for critical reading of an earlier version of this manuscript, and Zheng Wei Shao for valuable discussions.

Correspondence should be addressed to Andreas Burkhalter, Department of Anatomy and Neurobiology, Washington University School of Medicine, $660 \mathrm{~S}$. Euclid Avenue, Box 8108, St. Louis, MO 63110.

Copyright (C) 1997 Society for Neuroscience $0270-6474 / 97 / 177129-12 \$ 05.00 / 0$
}

preserved in the rat (i.e., forward circuits are directed to layer 4 and feedback connections tend to avoid layer 4). Thus differences in the laminar distribution of reciprocal forward and feedback connections can be used to delineate a hierarchy of visual areas in the rodent, similar to cat and monkey (Felleman and Van Essen, 1991; Coogan and Burkhalter, 1993).

In slices of rat visual cortex that preserve forward and feedback circuitry, we have found that activation of feedback inputs produces monosynaptic excitatory responses in the majority of striate cortical neurons which are virtually unopposed by disynaptic inhibition (Shao and Burkhalter, 1996). In parallel, we have demonstrated that feedback connections contact relatively few GABAergic interneurons (Johnson and Burkhalter, 1996) compared with thalamocortical inputs and local connections of thalamocortical-recipient neurons (White, 1989; Anderson et al., 1994). This organization suggests that feedback pathways may have special access to recurrent excitatory circuits (Douglas and Martin, 1991; Douglas et al., 1995) that could amplify feedback signals and influence activity generated by thalamocortical input under stimulus-specific conditions (Lamme, 1995; Zipser et al., 1996).

To test this notion anatomically, we examined the chain of polysynaptic feedback circuits in striate cortex consisting of feedback inputs from the secondary visual area lateromedial (LM) to neurons in V1 and in turn from feedback-recipient cells to neighboring neurons within area 17 of rat visual cortex. We accomplished this using a combination of anterograde degeneration to selectively label feedback connections and biotinylated dextran amine (BDA) to label feedback-recipient neurons and their local axon collaterals in area 17. 


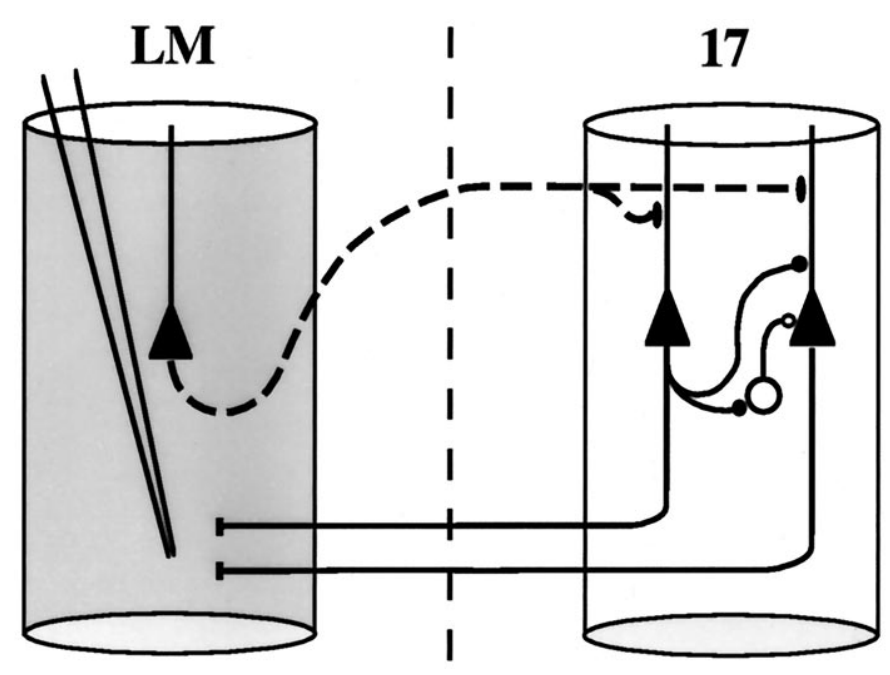

Figure 1. Methodology. Forward projecting neurons in area 17 (filled triangles, right cylinder) are retrogradely labeled after BDA injection into area LM (left cylinder). BDA injection was preceded by injection of NMDA (Jiang et al., 1993) resulting in Golgi-like filling of distal dendrites and labeling of short-range local axon collaterals (filled circles). In addition, BDA labels feedback axon terminals in area 17 (filled ellipses). Feedback-projecting neurons (filled triangle, left cylinder) are chemically lesioned by NMDA injection into area LM, causing selective anterograde degeneration of feedback axons (dotted lines) and terminals (filled ellipses). Short-range local axon collaterals of forward-projecting neurons, however, remain ultrastructurally intact. Axon terminals and dendrites of inhibitory interneurons (open circles) are identified by postembedding staining for GABA.

\section{MATERIALS AND METHODS}

General. Our approach to study polyneuronal feedback circuits is similar to that described by White et al. (1992). The underlying principle is explained in Figure 1. Forward projecting neurons in area 17 were retrogradely labeled after BDA injection into the secondary visual area LM (Coogan and Burkhalter, 1993). Injection of BDA was immediately preceded by small quantities of NMDA to promote complete filling of dendrites and axon collaterals of forward-projecting neurons in area 17 (Jiang et al., 1993). After a $1 \mathrm{~d}$ interval, which is sufficient for complete filling of forward-projecting neurons with BDA (Jiang et al., 1993), area LM was lesioned by local injection of NMDA (see below). Although BDA labeled both feedback pathways and local collaterals of forwardprojecting neurons within area 17 , only feedback terminals underwent anterograde degeneration, identified by characteristic ultrastructural changes (Jones and Powell, 1970; Peters et al., 1991) consisting sequentially of: (1) darkening cytoplasm with little change in organelles, (2) loss of synaptic vesicles and mitochondrial cristae, (3) shrinkage and distortion of terminals, (4) disappearance of mitochondria, and (5) engulfment by "reactive glial" processes.

Experiments were performed on nine adult Long Evans rats (200-230 gm body weight). All experiments adhered to policy on the use of animals in neuroscience research as described by the United States Public Health Service, National Institutes of Health guidelines, and the United States Animal Welfare Act and outlined by the Society for Neuroscience. Animal care and experimental protocols were also submitted and approved by local committee review at Washington University. For pathway tracing, animals were anesthetized using a mixture of ketamine and xylazine. Injections into LM were made at previously established coordinates $(1.0 \mathrm{~mm}$ anterior, $6.0 \mathrm{~mm}$ lateral to the lambda suture; Coogan and Burkhalter, 1993) through small burr holes. All injections were made by applying brief (5-15 msec) air pressure pulses to the back of a glass micropipette (inner tip diameter $=12-18 \mu \mathrm{m})$ with a Picospritzer (General Valve, Fairfield, NJ). Chemicals were obtained from Sigma (St. Louis, MO) except where noted otherwise.

$N M D A$-enhanced BDA labeling. In four animals, BDA injection was immediately preceded by injection of NMDA into LM $[\sim 0.05-0.1 \mu \mathrm{l}$ of $10 \mathrm{~mm}$ NMDA in $0.01 \mathrm{~m}$ phosphate buffer (PB), pH 7.0]. BDA (Molecular Probes, Eugene, OR) $(10,000 \mathrm{MW} ; 0.1-0.15 \mu \mathrm{l}$ of $10 \% \mathrm{BDA}$ in 0.01
M PB, $\mathrm{pH} 7.25$ ) was then slowly injected over a period of $\sim 15-20 \mathrm{~min}$. On the following day, LM was lesioned by NMDA injection $(0.25 \mu \mathrm{l}$ of 120 $\mathrm{mm}$ over $20 \mathrm{~min}$ ) at the same location. Animals were allowed to survive $4 \mathrm{~d}$ after lesion, a period determined to be optimal for ultrastructural identification of degenerating terminals in preliminary experiments (see below).

Animals were anesthetized deeply with pentobarbital $(80 \mathrm{mg} / \mathrm{kg})$ and perfused transcardially with a brief rinse of $0.1 \mathrm{M} \mathrm{PB}, \mathrm{pH} 7.4$, followed by a phosphate buffered mixture of $1 \%$ paraformaldehyde and $2.5 \%$ glutaraldehyde, $\mathrm{pH}$ 7.4. Brains were stored in the same fixative for $1 \mathrm{hr}$. Coronal sections were cut at $50 \mu \mathrm{m}$ using a vibratome and collected in four alternating series for light and electron microscopic examination of BDA, silver impregnation of degenerating fibers, and electron microscopic study of degeneration.

$B D A$ localization. Sections were preincubated for $30-45 \mathrm{~min}$ in $0.1 \mathrm{M}$ PB containing $2 \%$ normal rabbit serum and $0.3 \%$ Triton X-100 for light microscopy or $0.05 \%$ Triton X-100 for electron microscopy. After several brief rinses with $\mathrm{PB}$, sections were incubated in HRP-avidin-biotin complex (ABC Elite-Kit, Vector Laboratories, Burlingame, CA; double strength) in $0.1 \mathrm{M} \mathrm{PB}$ overnight at $4^{\circ} \mathrm{C}$ on a rotator. The next day, sections were thoroughly rinsed with $\mathrm{PB}$ and reacted using 3,5-diaminobenzidine (DAB) with nickel and cobalt enhancement (Adams, 1981). Sections for light microscopy were rinsed and dried on glass slides, dehydrated in ethanol, cleared in xylene, and coverslipped with DPX. Selected sections were counter-stained with neutral red.

Electron microscopy. Alternate sections were rinsed and post-fixed in $2 \% \mathrm{OsO}_{4}$ containing $0.05 \mathrm{M}$ potassium ferricyanide in $0.1 \mathrm{M} \mathrm{PB}(40 \mathrm{~min})$, dehydrated in an ascending series of ethanols (5 min each) with $1 \%$ uranyl acetate included in the $70 \%$ stage $(1 \mathrm{hr})$, and transferred from $100 \%$ ethanol to methanol (Fluka, Buchs, Switzerland) (3 x 5 min) Alcohol was removed by rinsing in propylene oxide (EM Sciences; $3 \times 15$ min). Finally, sections were infiltrated in a 1:1 mixture of propylene oxide and durcupan resin (Fluka) for 1-2 hr and placed on slides in drops of pure resin in a vacuum for $2 \mathrm{hr}$ to remove residual solvent. Sections were flat-embedded between slides and coverslips coated with plastic mold release agent (EM Sciences; $48 \mathrm{hr}$ at $\left.56^{\circ} \mathrm{C}\right)$.

Silver impregnation of degenerating axon terminals. Silver staining was performed according to the method of Fink and Heimer (1967; procedure II). The following steps optimized labeling: (1) storage of sections at $4^{\circ} \mathrm{C}$ for $3-6$ weeks in $10 \%$ formalin in $0.1 \mathrm{M} \mathrm{PB},(2)$ reaction in $0.025 \%$ potassium permanganate for $10 \mathrm{~min}$, (3) incubation in $2.5 \%$ uranyl nitrate (Fluka) for $10 \mathrm{~min}$, (4) incubation in $0.3 \%$ silver nitrate with $2 \%$ pyridine for $2 \mathrm{hr}$, and (5) transfer to freshly prepared ammoniacal silver nitrate for 2-3 min. Sections were reacted in Nauta-Gygax reducer and processed as described by Fink and Heimer (1967).

Time course of anterograde degeneration. Preliminary studies were performed in five animals to examine the progression of degeneration. For this purpose, NMDA and BDA were injected into area LM as described above, and animals were allowed to survive 1-5 d after LM was lesioned. Sections were collected in two series: for light microscopic examination of BDA labeling and for electron microscopic examination of degenerating profiles without BDA reaction. Unreacted sections were processed for electron microscopy as described above and examined for ultrastructural signs of degeneration (Jones and Powell, 1970; Peters et al., 1991) within the feedback projection zone in area 17.

Light and electron microscopy of forward-projecting neurons. Pairs of adjacent vibratome sections reacted alternately for BDA (Ni-Co/DAB) and degeneration (silver staining) were examined in the light microscope to identify retrogradely labeled forward projecting cells in area 17 within the densest region of feedback projections. Briefly, coverslips were removed and selected regions were cut out and glued onto blank capsules of resin. Blocks were trimmed to a mesa that included layers 1 and $2 / 3$ and long uninterrupted series of thin sections ( $\sim 85-90 \mathrm{~nm}$ thickness) were cut and collected alternately on copper and nickel formvar-coated polyslot grids (five to eight thin sections per grid). Copper grids were stained briefly with Reynold's lead citrate and examined with a JEOL 1200 EX transmission electron microscope at an accelerating voltage of $60 \mathrm{kV}$.

Nickel grids were reacted for GABA using immunogold labeling to further characterize both postsynaptic dendritic shafts and second, symmetric inputs made onto dendritic spines. Postembedding immunocytochemistry was performed according to Somogyi and Hodgson (1985), as modified by Freund and Gulyás (1991). Briefly, grids were processed by etching with $1 \%$ periodic acid and $1 \%$ periodate, preincubation in $1 \%$ BSA, and incubation in 1:1000 rabbit anti-GABA (Sigma), and incuba- 

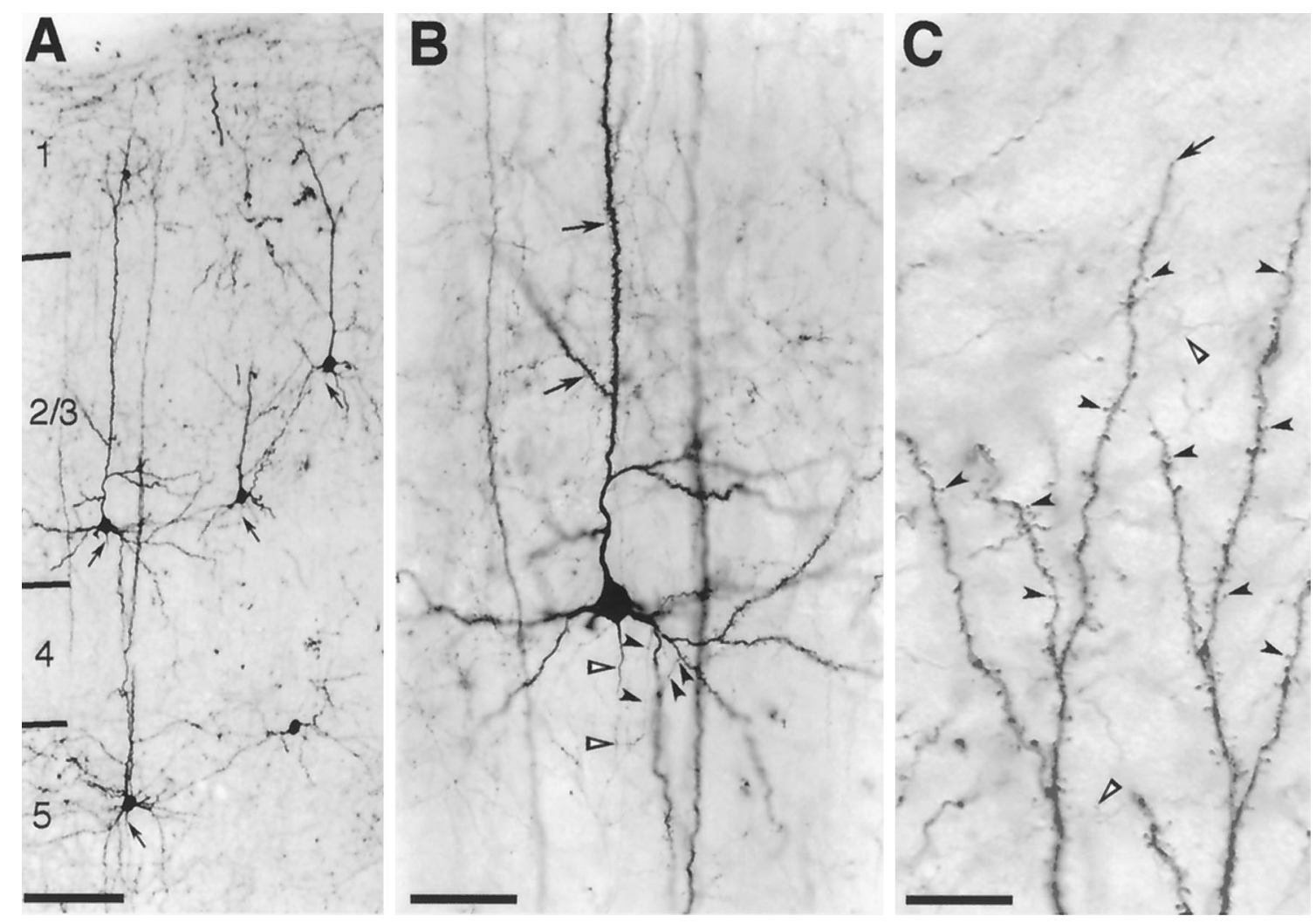

Figure 2. Photomicrographs of BDA-labeled forward-projecting neurons. $A$, Cluster of forward-projecting pyramidal neurons in area 17 after NMDA/BDA injection in extrastriate area LM, $4 \mathrm{~d}$ after lesion with NMDA. In addition to prominent dendritic labeling, axons are seen descending from labeled cell bodies (arrows). B, Forward-projecting neuron in lower layer 2/3. Main axon (open arrowheads) bifurcates close to the soma. Local collaterals form axonal boutons in vicinity of basal dendrites (filled arrowheads). Other BDA-labeled axons ramify in close proximity to apical dendrites (arrows). $C$, BDA-labeled apical dendrite in layer 1 of forward-projecting neuron located in lower layer 2/3, illustrating complete filling of dendrites (arrow). Filled arrowheads point to representative dendritic spines, which stud labeled dendrites. Open arrowheads show bouton termineax. Scale bars: $A$, $100 \mu \mathrm{m} ; B, 50 \mu \mathrm{m} ; C, 10 \mu \mathrm{m}$.

tion in $15 \mathrm{~nm}$ gold-conjugated goat anti-rabbit IgG. Each step was followed by thorough rinsing with deionized, distilled water. Pairs of grids were examined in the electron microscope and data were collected as described below. Briefly, one thin section per grid was used to identify all labeled presynaptic and postsynaptic structures. Profiles that did not make synaptic connections were followed in serial sections on the same grid until a synapse was identified or until the last section was reached. All labeled synaptic profiles were photographed at $20,000-27,000 \times$ magnification.

\section{RESULTS}

\section{Light microscopy}

Golgi-like retrograde tracing of forward projecting neurons

Retrogradely filled forward-projecting neurons in area 17 are illustrated in Figure 2. Without exception, BDA labeled neurons were pyramidal cells (Fig. $2 A$ ). The appearance of filled neurons was similar to that described in classic Golgi studies: filled neurons typically had a skirt of basal dendrites that radiated from the cell body and a single primary apical dendrite that gave off secondary branches near the soma (Fig. $2 B$ ) and formed an apical tuft in layer 1 (Fig. $2 C$ ). BDA filled neurons were present in all layers but were most numerous in layer $2 / 3$.

Examination of BDA labeled pyramidal cells at higher power (Fig. 2B,C) showed evidence for labeling of local axon collaterals of retrogradely labeled neurons (Fig. $2 B$ ) and Golgi-like filling of distal apical dendrites and dendritic spines (Fig. 2C). Each retrogradely labeled neuron had a clearly labeled main axon that descended from the cell body toward the white matter (Fig. 2A).
Because vibratome sections were relatively thin, however, the majority of axons was truncated near the cell body. In the example shown in Figure $2 B$, the main axon descended from the cell body and after a short distance gave off several collaterals that formed axonal boutons (arrowheads) in the vicinity of its basal dendrites. Such close encounters between BDA labeled axons and dendrites were quite common. The morphology of labeled axons resembled that seen in other species (Kisvárday et al., 1986; Gabbott et al., 1987; McGuire et al., 1991) with boutons made mostly en passant and less frequently bouton termineaux (Fig. 2C).

\section{Identification of local axon collaterals of forward projecting neurons}

Preliminary evidence for anterograde degeneration of feedback connections was obtained in a series of cases perfused 1-5 d after area LM was lesioned with NMDA. At day 1 after lesion, the pattern of labeling consisted of a small patch of retrogradely labeled cells in layer $2 / 3$ of area 17 embedded in a dense network of feedback and local axon collaterals (Fig. $3 A$ ). By day 2 after lesion, however, the pattern was obviously different. The projection zone contained Golgi-like labeled pyramidal cells (Fig. 3B) but axonal labeling was much sparser than at day 1 . Inspection at higher power (Fig. $3 E$ ) revealed two distinct populations of axons. A small number consisted of intact axons that were indistinguishable from those labeled at day 1 . A second, much larger, population of axons appeared to be broken up into short segments with periodic swellings which are clear signs of degeneration (Fig. $3 E$; 

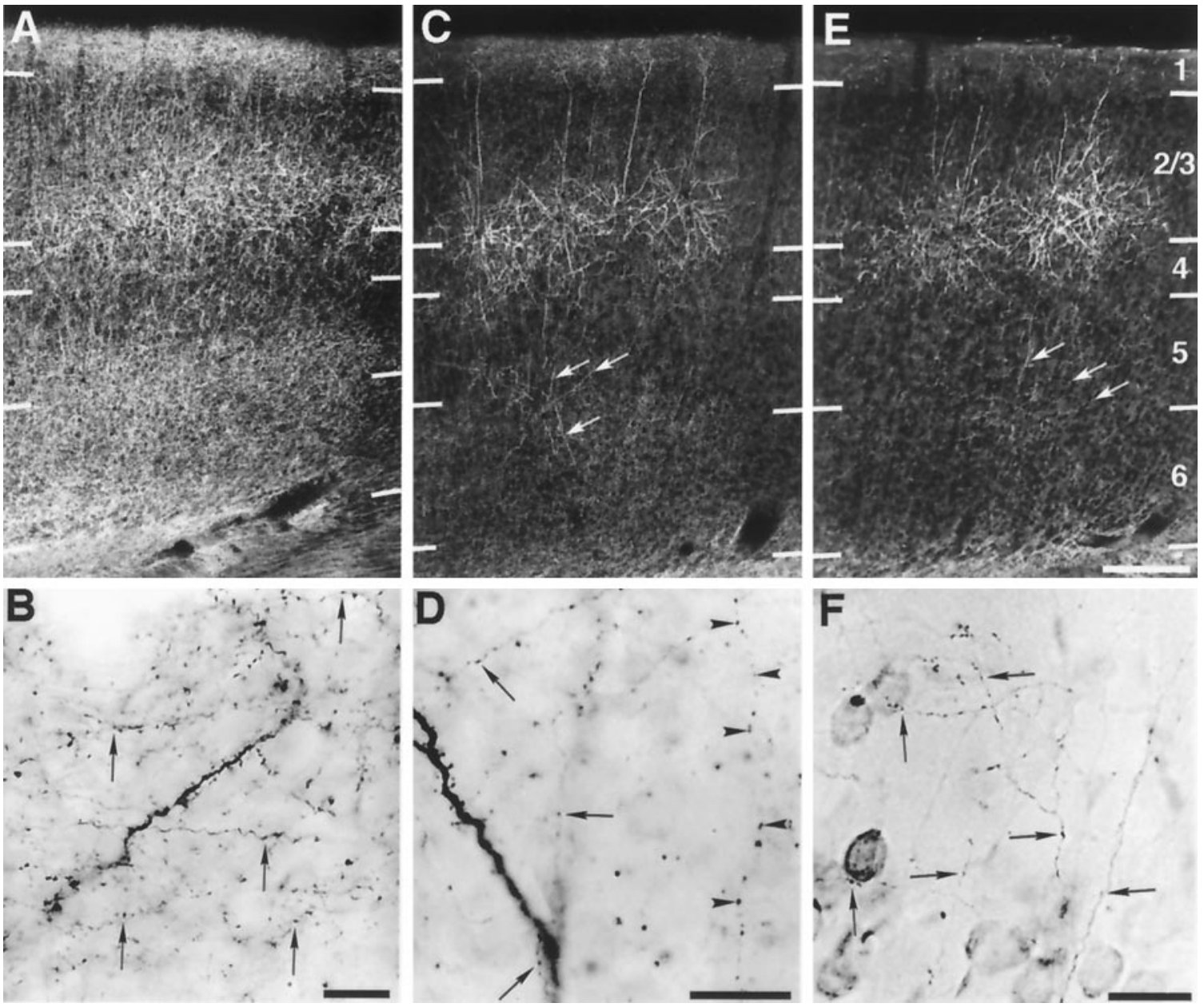

Figure 3. Time course of anterograde degeneration in feedback pathways, area 17. A, Dark-field photomicrographs show BDA labeling in area 17 in rat killed $1 \mathrm{~d}$ after area LM was lesioned. Retrogradely labeled neurons in lower layer $2 / 3$ embedded in a dense network of BDA-labeled fibers. $B$, Bright-field photomicrograph shows layer 1 at higher magnification from the case illustrated in $A$. Labeling consists of axons bearing synaptic boutons (arrows) and dendrites (center of field). $C$, At day 2 after lesion, however, labeled feedback axons are less visible under dark-field illumination. Labeling continues to be abundant, however, in retrogradely labeled cell bodies and dendrites of layer $2 / 3$ forward-projecting neurons and their local axon collaterals, which ramify within layers $2 / 3$ and 5 (arrowheads). D, At higher power, two distinct populations of axons are seen. One is normal in appearance (arrows), identical to those at day 0, but the other is broken into chains of labeled puncta (arrowheads), representing short-range axon collaterals of forward-projecting neurons and feedback axons, respectively. $E$, At day 4 after lesion, labeling was similar to day 2 after lesion. $F$, However, at higher power degenerating axons had completely disappeared, leaving only normal intact axons (arrows). Coronal sections are shown. Scale bars: top row, $0.25 \mathrm{~mm}$; bottom row, $40 \mu \mathrm{m}$.

arrowheads). Also unlike labeling at day 1 after lesion, numerous BDA labeled puncta were scattered throughout the feedback projection zone. Importantly, retrogradely labeled cell bodies and dendrites appeared normal $2 \mathrm{~d}$ post-lesion. The same was true for axons that emerged from retrogradely labeled neurons in layer $2 / 3$ and terminated in layers $2 / 3$ and 5 (Fig. 3B,C), a well-described local axon pathway (Burkhalter, 1989). This strongly suggests that axon collaterals of forward-projecting neurons were unaffected by LM lesions.

\section{Labeling of feedback connections}

Figure $4 A$ illustrates the position of the NMDA injection in area LM (asterisk) and the pattern of resulting anterograde degeneration. Under dark-field illumination, silver reaction product appeared bright. The injection was centered in lower layers and resulted in a cup-shaped lesion. In area 17, axonal degeneration occurred in a bilaminar pattern (Fig. $4 A, D$ ), and resembled the laminar pattern of feedback inputs (Coogan and Burkhalter, 1993). Silver reaction product extended medially from the edge of the lesion in LM into the projection zone in area 17 and was most dense in layer 1 and in layer 6 (arrowheads). Weaker labeling was observed in layers $2 / 3$ and 5 and was almost absent in layer 4 . In contrast, degeneration in anterolateral (AL) extrastriate areas, medial complex (Mx), and far lateral complex (FLx), all known to receive forward input from LM (Coogan and Burkhalter, 1993), typically included layer 4 (Fig. $4 A$ ). Prominent degeneration was found subcortically in the lateral posterior nucleus (Fig. $4 B$ ) and in deep layers of the superior colliculus (Fig. $4 C$ ). However, labeling was relatively absent in upper layers of the superior colliculus and in the lateral geniculate nucleus. This pattern of cortical and subcortical labeling is consistent with known projections from area LM (Coogan and Burkhalter, 1993), providing confidence that the lesion was confined to this area.

\section{Electron microscopy}

Electron microscopic evidence for anterograde degeneration

The cases illustrated in Figure 3 were examined ultrastructurally to determine whether feedback terminals degenerated synchro- 

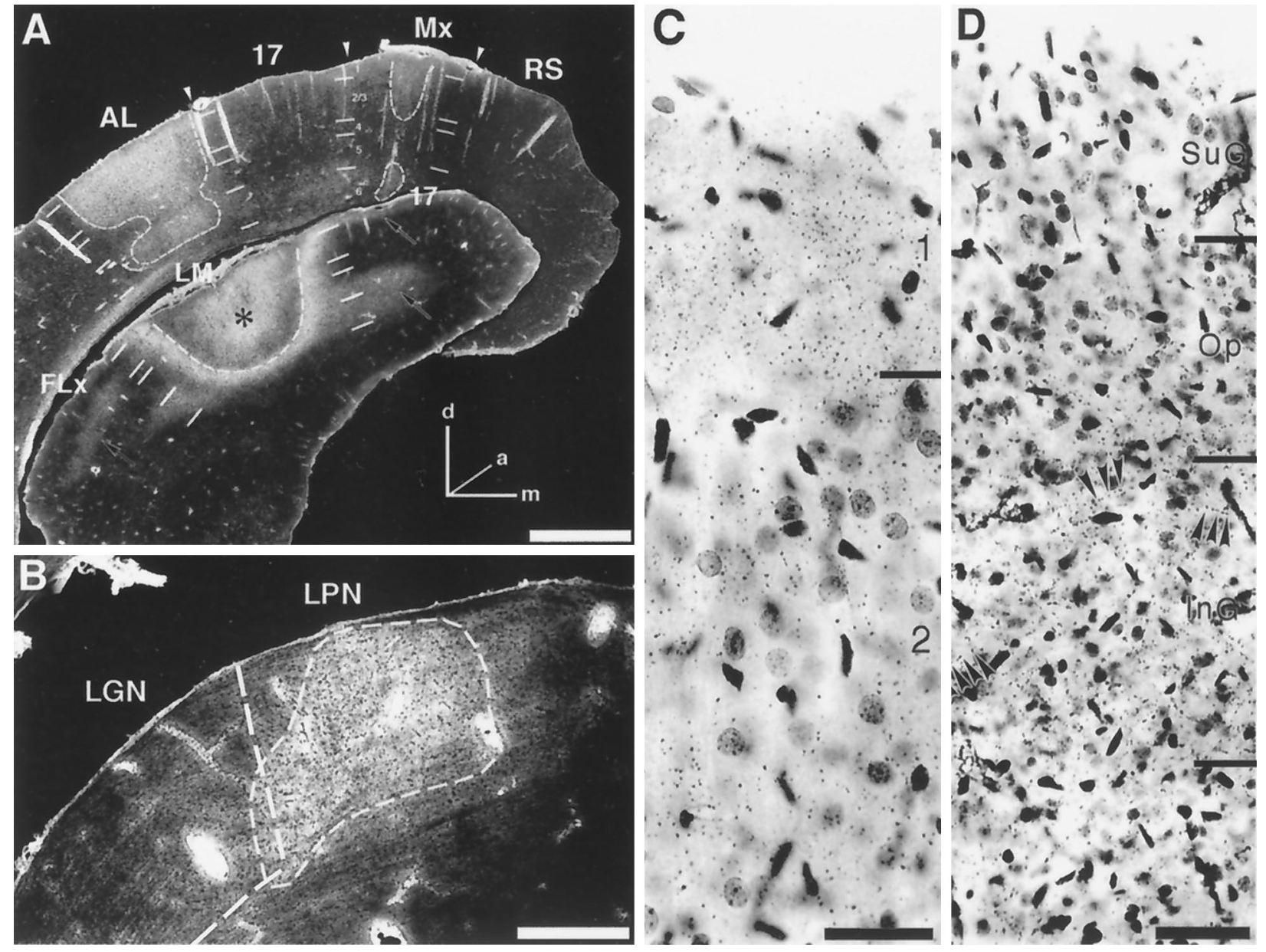

Figure 4. Pattern of anterograde degeneration after area LM was lesioned. A, Coronal sections through visual cortex, dark-field illumination. Asterisk shows NMDA injection site centered in LM. Dotted line indicates region of cell loss determined from Nissl-stained adjacent section. Silver-labeled (bright) degenerating feedback projections (arrows) are seen in superficial and deep layers of area 17. Forward projections are seen lateral to LM. Additional labeling of forward projections is found in anterolateral extrastriate area $(A L)$ and medial extrastriate cortex $(M x)$. $R S$, Retrosplenial cortex; $F L x$, far lateral complex. $B$, Labeling of degenerating corticothalamic projections to the lateral posterior nucleus $(L P N)$ of the thalamus. $C$, Bright-field photomicrograph of area 17, upper layers, showing grains of silver precipitate in layers 1 and $2 / 3$ of the feedback projection zone. $D$, Bright-field photomicrograph of silver-impregnated axons in the superior colliculus. Degenerating axons (arrowheads) are densest in the inferior gray (In $G$ ) and lower optic layers $(O p)$ but are absent from the superficial gray $(S u G)$ consistent with projections originating in extrastriate cortex. Dorsal, up; Medial, right. $L G N$, Lateral geniculate nucleus. Scale bars: $A, 1 \mathrm{~mm} ; B, 0.5 \mathrm{~mm} ; C, 50 \mu \mathrm{m}$.

nously and to ensure that no newly degenerating terminals were present at longer survival times. For this purpose, we restricted our examination to unreacted sections to avoid potential confusion with BDA labeling. Briefly, all degenerating terminals exhibited ultrastructural changes consistent with the description of Jones and Powell (1970) for nonfilamentous degeneration. The earliest signs of degeneration observed in axon terminals were darkened cytoplasm and reduced numbers of synaptic vesicles. At later stages of degeneration ( 3 and $4 \mathrm{~d}$ after lesion), however, the terminal cytoplasm became increasingly electron dense, and synaptic vesicles and mitochondria disappeared (Figs. 5B, 6C,D). Later than $4 \mathrm{~d}$ after lesion, degenerating terminals were still observed but were more difficult to identify because of their severely shrunken size and engulfment by reactive glial processes (not shown). Importantly, at 4-5 d after lesion, no evidence was found for terminals in earlier stages of degeneration, indicating the absence of newly degenerating terminals at these time points. We therefore restricted our observation to animals killed at day 4 after lesion.

Despite radical changes in the presynaptic terminals of degen- erating feedback synapses, the only consistent ultrastructural change in the postsynaptic site was an occasional increase in the concavity of the postsynaptic membrane and synaptic density (Figs. $5 B, 7 B$ ). All postsynaptic sites had an intact synaptic cleft and a clearly identifiable postsynaptic density. Neuronal cell bodies, nuclei, and dendrites examined at all stages had normal ultrastructure, as described by Peters et al. (1991).

\section{Ultrastructure of labeled synaptic elements}

In the electron microscope, we were able to distinguish between normal and degenerated BDA labeled axon terminals. Examples of each type are shown in Figure 5. Ultrastructurally, the degenerating axon terminal shown in Figure $5 A(t+)$ exhibited significant shrinkage, cytoplasmic condensation, and loss of synaptic vesicles and mitochondria, consistent with late stages of degeneration. Within this terminal electron dense $\mathrm{Ni}-\mathrm{Co} / \mathrm{DAB}$ was patchy within both the cytoplasmic space and the apparent vestige of a mitochondrion. This stands in contrast to the normal ultrastructural appearance of a nearby unlabeled terminal $(t-)$. The axon terminal illustrated in Fig- 
Figure 5. Ultrastructural distinction between BDA-labeled intrinsic axon terminals of forward-projecting neurons and feedback terminals in area 17, after lesion day 4. $A$, Electron micrograph of a BDA-labeled degenerating feedback terminal $(t+)$. The terminal is shrunken in appearance and devoid of normal synaptic vesicles. Only a remnant of the mitochondrion remains (beneath the $t+$ ). A nearby unlabeled terminal $(t-)$ that also makes an asymmetric connection with a dendritic spine $(s)$ is shown for comparison. $B$, Nearby BDAlabeled axon terminal $(t+)$ of a local axon collateral of a forward-projecting neuron in area 17. The terminal is ultrastructurally intact, with clearly visible synaptic vesicles and mitochondrion. The terminal makes an asymmetric synapse (arrow) with an unlabeled dendritic spine (s). Scale bar (shown in $A$ for $A$ and $B$ ): $0.5 \mu \mathrm{m}$.
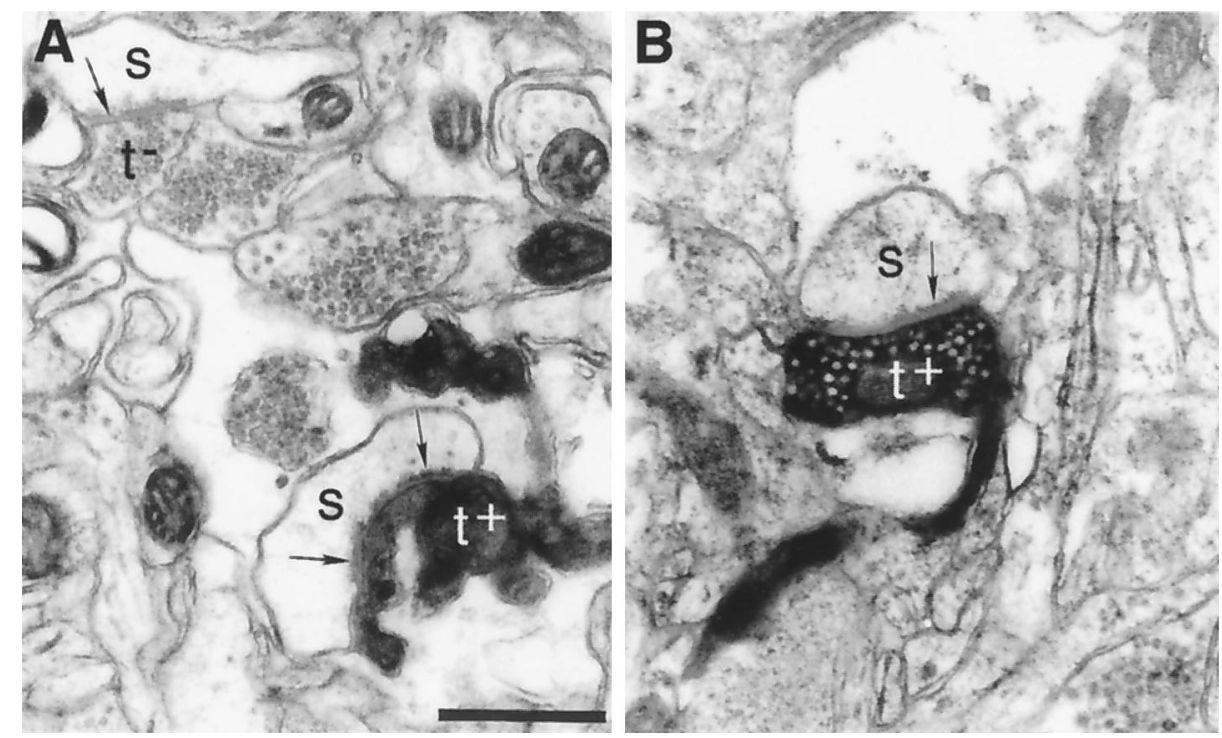

ure $5 B(t+)$ contained similarly electron dense precipitate that uniformly filled the cytoplasm. Unlike degenerating terminals, normal terminals contained mitochondria and well-defined synaptic vesicles. Consistent with our methodology, the most likely interpretation these results is that ultrastructurally normal, BDA labeled terminals are intrinsic axon collaterals of forward-projecting neurons, whereas those that are degenerating are feedback terminals.

Figure $6 A$ shows the typical appearance of a BDA labeled apical dendrite. Electron dense reaction product was deposited along parallel arrays of microtubules (arrowheads) within dendritic shafts $(d)$ and along unidentified membranous and cytoskeletal elements within dendritic spines (Fig. $6 A-C$ ). BDA labeling clearly extended through the thin spine neck into the head of labeled spines $(s)$. Nearby unlabeled dendritic shafts $(u d)$ and spines (us) are shown for comparison. Relatively little precipitate was present directly apposed to plasma membranes even in intensely stained dendrites, facilitating the distinction between asymmetric and symmetric postsynaptic densities.

As classically described (Peters et al., 1991), asymmetric connections were associated with relatively thick postsynaptic specializations and with presynaptic terminals that contained uniformly small, round vesicles (Fig. 6A). In contrast symmetric connections had a very thin postsynaptic density and were associated with terminals containing pleiomorphic or flattened vesicles (Fig. 6B, arrow). These two types of terminals are generally considered to be associated with excitatory and inhibitory function, respectively (Colonnier, 1981).

\section{Postsynaptic targets of feedback pathways}

Additional feedback terminals are illustrated in Figures $6 C, D$, and $7 B$. All feedback terminals identified in this study $(36 / 36)$ were found to terminate at thick postsynaptic specializations, consistent with excitatory function (Shao and Burkhalter, 1996). Figures $6 C, D$ and $7 B$ illustrate feedback terminals that synapse with dendritic spines and shafts, respectively.

Postsynaptic targets of feedback terminals were tabulated (Tables 1,2$)$. The majority of feedback connections were made with dendritic spines $(94.4 \%$; 34/36) and the remainder with dendritic shafts $(5.6 \% ; 2 / 36)$. Of the latter, one input terminated on a BDA-negative spiny dendrite (Fig. $7 B$ ) that was found to be
GABA-negative. The second input was to a dendritic shaft that expressed very weak GABA immunoreactivity (not shown). This indicates that $\sim 97 \%$ of feedback terminals $(35 / 36)$ terminate on pyramidal neurons and only $\sim 3 \%(1 / 36)$ provide input to GABAergic neurons.

Figure $6 C, D)$, in addition, provides evidence that feedback axons directly contact forward-projecting neurons. The dendritic spines illustrated in these panels contain $\mathrm{Ni}-\mathrm{Co} / \mathrm{DAB}$ precipitate indicating that they are BDA labeled spines of forward-projecting neurons. Further examination revealed that all feedback inputs to identified forward-projecting neurons (7/7) contacted dendritic spines (Table 1). No labeled or unlabeled dendritic spines postsynaptic to feedback inputs $(0 / 34)$ were found to receive a second symmetric input.

\section{Postsynaptic targets of intrinsic axons of forward projecting cells}

The ultrastructural appearance of local axon collaterals of forward-projecting neurons and their postsynaptic targets in area 17 is further illustrated in Figure 7. Figure $7 C$ shows a BDA labeled axon terminal that makes an asymmetric connection with a labeled dendritic spine of a cell that projects from area 17 to area LM. Figure $7 D$ shows a similar connection with the shaft of an identified forward projecting neuron.

Similar to feedback connections, the majority of postsynaptic targets of forward projecting cells in area 17 were dendritic spines $(93.6 \% ; 59 / 63)$. Of these, a substantial proportion were found to contain BDA $(13.5 \%$; 8/59), indicating that forward projecting cells make synaptic connections with other forward-projecting neurons. Similarly, the majority of dendritic shafts postsynaptic to forward projecting cells $(75 \% ; 3 / 4)$ contained BDA labeling, and therefore were identified as shafts of forward-projecting neurons. GABA labeling in the single BDA-negative shaft was equivocal (not shown), and no definitive information was obtained ultrastructurally.

Of the dendritic spines postsynaptic to local axon collaterals of forward-projecting neurons $(n=59)$, one spine was identified that received a second symmetric input (Fig. $7 A_{1}$ ). Reaction for GABA in a serial sections indicated that this terminal contained GABA (Fig. $7 A_{2}$ ). 

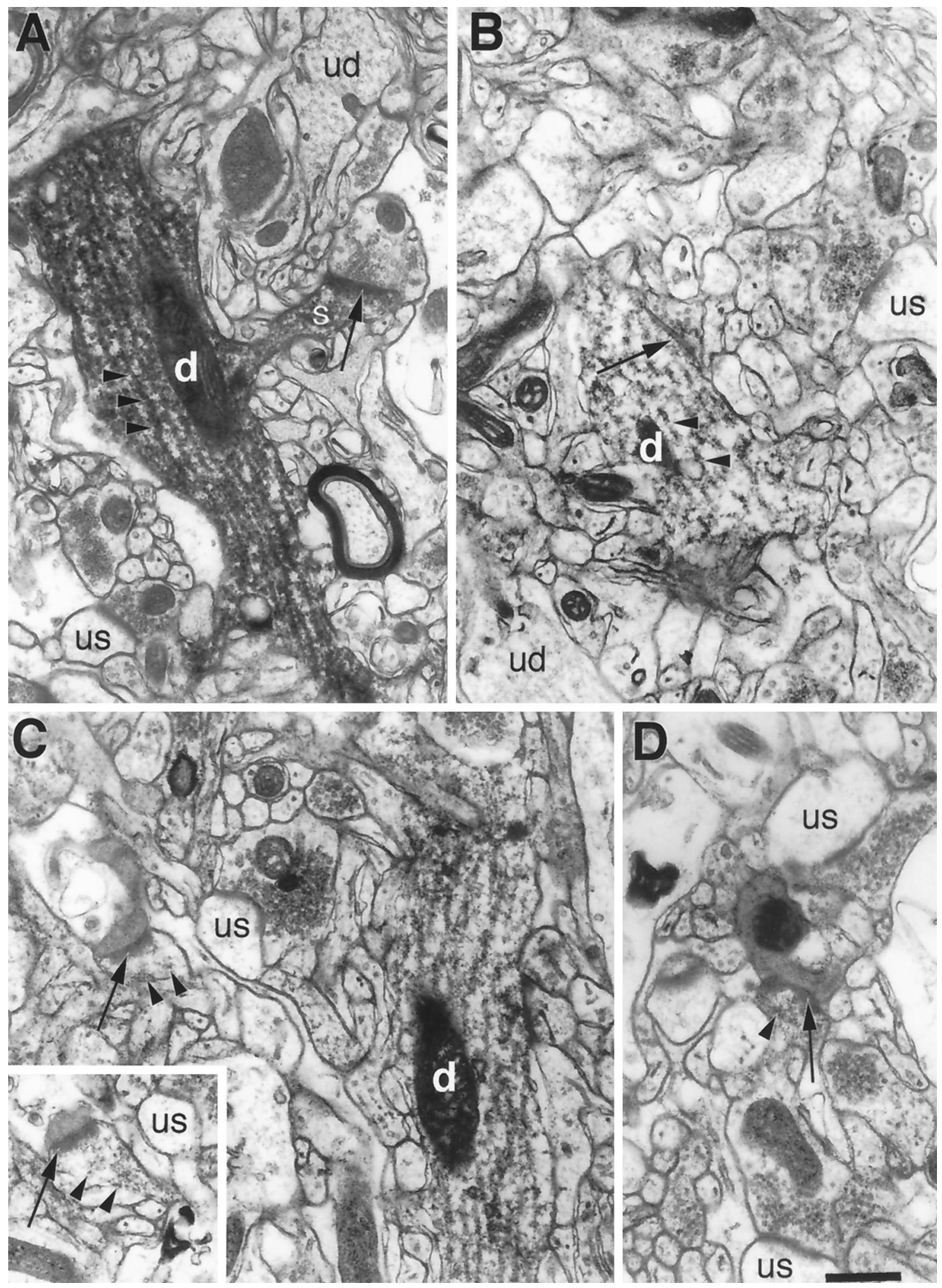

Figure 6. Feedback inputs to forward-projecting cells in area 17, layer 2/3. A, Ultrastructural appearance of BDA-labeled forward-projecting cell dendrite. $\mathrm{Ni}-\mathrm{Co} / \mathrm{DAB}$ reaction product is concentrated along parallel arrays of microtubules (arrowheads) in the dendritic shaft $(d)$. Labeling is also found in a dendritic spine ( $s$ ) that receives an unlabeled asymmetric input (arrow). A nearby unlabeled spine (us) is shown for comparison. B, A weakly BDA-labeled dendritic shaft $(d)$ receives an unlabeled symmetric input containing flattened vesicles and a thin postsynaptic specialization. A nearby unlabeled dendritic shaft $(u d)$ and spine (us) are shown for comparison. $C$, Degenerating feedback terminal makes an asymmetric contact (arrow) with a BDA-labeled spine of a forward-projecting neuron. Labeling in the spine (arrowhead) is relatively weak, but clearly present in comparison to a nearby unlabeled spine (us). Inset, Same spine as in $C$ showing more prominent BDA labeling (arrowheads). $D$, Additional example of feedback input to BDA-labeled dendritic spine of a forward-projecting neuron. Scale bar: $A-D, 0.5 \mu \mathrm{m}$. 

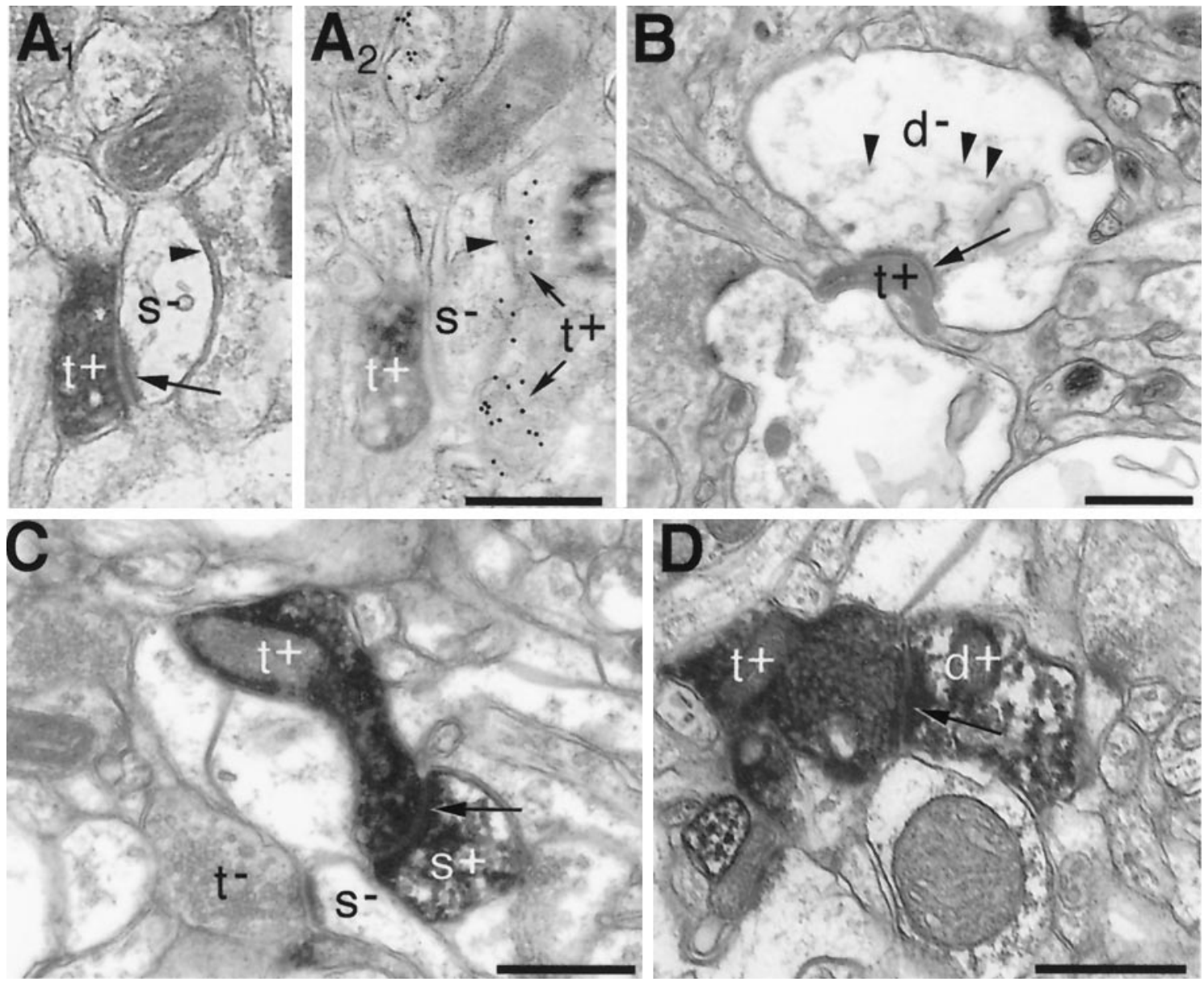

Figure 7. $A_{1}$, BDA-labeled axon terminal of local short-range collateral $(t+)$ of a forward-projecting cell in area 17 makes a local asymmetric connection (arrow) with an unlabeled spine that receives a second unlabeled symmetric input (arrowhead). $A_{2}$, Serial thin section shows clustering of gold particles over the second input indicating that it is the axon terminal of a GABAergic interneuron. $B$, Degenerating feedback terminal $(t+)$ in upper layer 1 of area 17 forms an asymmetric connection (arrow) with an unlabeled dendritic shaft $(d-$ ). The presence of a dendritic spine projecting off to the right combined with a scarcity of additional synaptic inputs strongly suggests that it originates from a pyramidal neuron. $C$, BDA-labeled local short-range axon terminal $(t+)$ of a forward-projecting neuron in area 17 makes an asymmetric connection (arrow) with a BDA-labeled dendritic spine of a forwardprojecting neuron. A nearby unlabeled synapse is shown for comparison. $D$, A similar connection $(t+$, arrow) is made with an identified dendritic shaft $(d+)$ of a forward-projecting neuron. Scale bars: $0.5 \mu \mathrm{m}$.

Table 1. Asymmetric synaptic inputs to forward-projecting cells

\begin{tabular}{|c|c|c|c|c|c|c|c|c|c|}
\hline \multirow[b]{2}{*}{ Layer $^{a}$} & \multicolumn{3}{|l|}{ Spine } & \multicolumn{3}{|l|}{ Shaft } & \multicolumn{3}{|l|}{ Total } \\
\hline & FWI & FB & Unlab & FWI & FB & Unlab & FWI & FB & Unlab \\
\hline 1 & $5(6.1)$ & $5(6.1)$ & $72(87.8)$ & $2(22.2)$ & 0 & $7(77.8)$ & $7(7.7)$ & $5(5.5)$ & 79 (86.8) \\
\hline $2 / 3$ & $3(12)$ & $2(8)$ & $20(80)$ & $1(100)$ & 0 & 0 & $4(15.4)$ & $2(7.7)$ & $20(76.9)$ \\
\hline Total & $8(7.5)$ & $7(6.5)$ & $92(86.0)$ & $3(30)$ & 0 & $7(70)$ & $11(9.4)$ & $7(6.0)$ & 99 (84.6) \\
\hline
\end{tabular}

FWI, Forward-projection cell intrinsic axon collateral; FB, feedback terminal; Unlab, unlabeled asymmetric terminal.

${ }^{a}$ Cortical layer in which synaptic connections were examined.

\section{Comparison of postsynaptic targets}

A summary of the postsynaptic targets of local axon collaterals of forward projecting cells and feedback projections in area 17 is shown in Figure 8. For a point of reference, the postsynaptic sites selected by each pathway were compared with those contacted by unlabeled asymmetric synapses ("neuropil") in upper layers of area 17 determined in a previous study (Johnson and Burkhalter, 1996). Data for postsynaptic targets of feedback connections was pooled with 113 additional feedback inputs studied previously (Johnson and Burkhalter, 1996).
Similar to the neuropil ( $\sim 86 \%)$ most feedback inputs $(96.6 \%$; $144 / 149)$ and local collaterals of forward-projecting neurons (93.6\%; 59/63) targeted spines of pyramidal neurons. In addition to these axospinous local inputs, many short-range local collaterals of forward-projecting neurons contacted dendritic shafts of other forward-projecting neurons (3/4), bringing the total input to pyramidal neurons to at least $\sim 97 \%$. The remaining $\sim 3 \%$ of local axon terminals most likely contact dendritic shafts of GABAergic neurons. This proportion is significantly lower than the $\sim 10 \%$ of unlabeled asymmetric connections which synapse with GABAer- 
Table 2. Postsynaptic targets of local collaterals of forward-projecting cells and feedback projections

\begin{tabular}{|c|c|c|c|c|}
\hline \multirow[b]{2}{*}{ Layer $^{a}$} & \multicolumn{2}{|c|}{ Forward axons } & \multicolumn{2}{|c|}{ Feedback axons } \\
\hline & Spine $^{b}$ & Shaft & Spine & Shaft \\
\hline 1 & $43(95.6)$ & $2(4.4)$ & $29(93.5)$ & $2(6.5)$ \\
\hline $2 / 3$ & $16(88.9)$ & $2(11.1)$ & $5(100)$ & $0(0)$ \\
\hline Total & $59(93.7)$ & $4(6.3)$ & $34(94.4)$ & $2(5.5)$ \\
\hline
\end{tabular}

${ }^{a}$ Cortical layer in which synaptic connections were examined.

${ }^{b}$ Spine and shaft inputs, respectively, are expressed within parentheses as percent of total identified inputs within indicated layer.

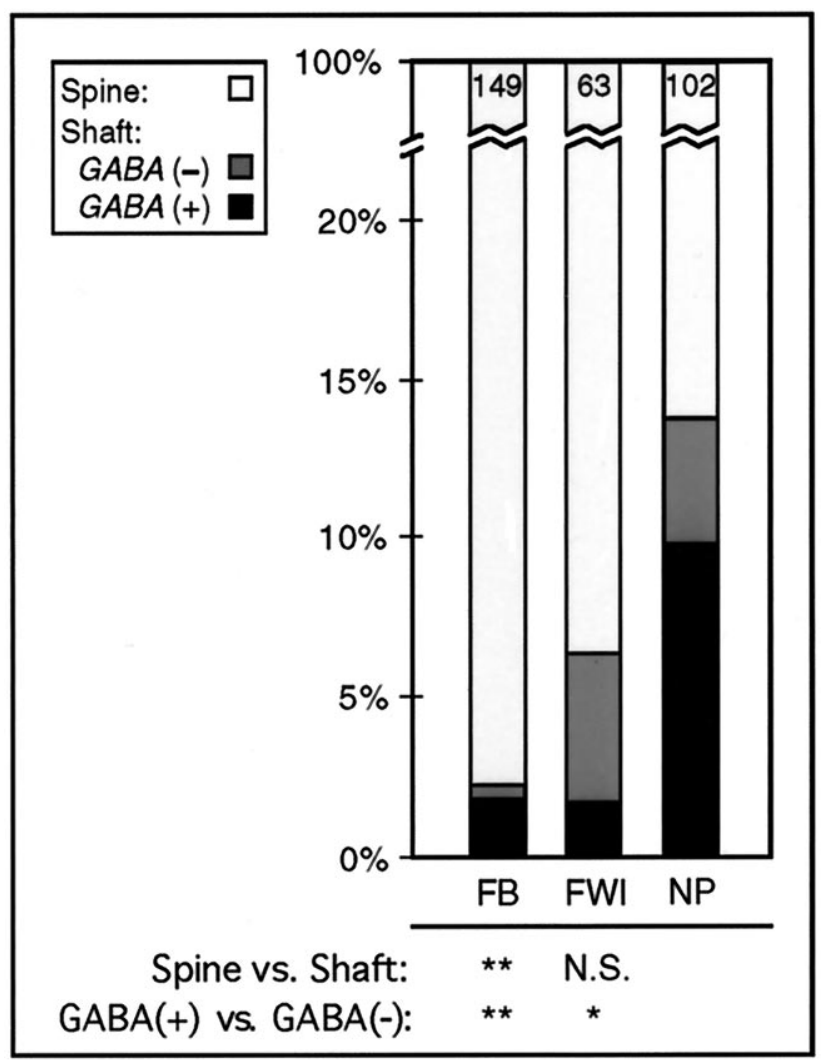

Figure 8. Comparison of postsynaptic targets of short-range intrinsic axon terminals of forward-projecting cells $(F W I)$, feedback pathways $(F B)$, and unlabeled connections in the neuropil $(N P)$ (Johnson and Burkhalter, 1996) in layers 1 and $2 / 3$ of area 17. Proportion of spines, $G A B A(-)$ shafts and $G A B A(+)$ shafts indicated by shaded and hatched bars as shown in legend. Feedback connections are made selectively with dendritic spines (Fisher's exact test, $p<0.01$ ) and with GABA $(-)$ targets $(p<0.01)$ compared with neuropil connections. Short-range axon collateral terminals of forward-projecting neurons also exhibited specificity for GABA $(-)$ targets $(p<0.05)$, but formed synapses with similar proportions of spines and shafts compared with the neuropil.

gic targets ( $p<0.05$; Fisher's exact test) observed in the neuropil. This strongly suggests that local axon collaterals of forwardprojecting neurons preferentially communicate with other pyramidal cells.

Similar to local axon collaterals of forward projecting cells, feedback pathways provided relatively little input to GABAergic neurons $(2.7 \%$; 4/149) compared with connections in the neuropil ( $p<0.01$; Fisher's exact test). However, unlike short-range local axon collaterals of forward-projecting neurons, feedback inputs showed a different subcellular distribution of their inputs to pyramidal cells with a greater tendency to synapse with dendritic spines ( 97\%; 144/149) rather than dendritic shafts compared with connections in the neuropil ( $p<0.01$; Fisher's exact test).

\section{Anatomical strength of feedback inputs to forward projecting cells}

To obtain an estimate of the strength of feedback connections to identified forward projecting cells, we determined the proportion of degenerating synaptic inputs relative to all labeled and unlabeled asymmetric inputs to BDA labeled dendrites in layer 1 and upper layer $2 / 3$ of area 17 (Table 2). Feedback connections accounted for $\sim 8 \%$ of all asymmetric inputs to forward projecting cells. Although these data suggest that feedback connections provide only a minor contribution of the total synaptic input of forward projecting cells, it is comparable to that of geniculocortical input to layer 4 striate cortical neurons in the cat (Peters and Payne, 1993) and thalamocortical input to pyramidal cells in mouse somatosensory cortex (White, 1989).

\section{DISCUSSION}

Our investigation of the corticocortical circuit linking extrastriate visual area LM and area 17 in the rat has shown that feedback connections provide input directly to neurons in V1 that make the reciprocal forward projection. In addition, feedback-recipient neurons are strongly connected to pyramidal cells within area 17 but contact approximately three- to fourfold fewer GABAergic neurons than connections in the neuropil. Furthermore, many local collaterals of forward-projecting neurons provide input to other forward projecting cells, suggesting that these cells as a population are strongly interconnected. This connectivity suggests that a subset of pyramidal cells in V1 amplify feedback input in a local excitatory network and then send activity back upstream.

\section{Technical considerations}

Anterograde axonal degeneration combined with various methods of intracellular filling (Fig. 1) has become a well accepted method for differentiating afferent inputs from local collaterals in the electron microscope (Somogyi, 1978; Freund and Somogyi, 1983; Buhl et al., 1989; White, 1989; White et al., 1992). Our approach was similar to that of White et al. (1992), but we chose BDA because it provides superior filling of distal dendrites of projection neurons (Jiang et al., 1993), but like HRP, has no known selectivity for neuronal subtypes (Veenman et al., 1992; Jiang et al., 1993).

Challenges associated with using degeneration as an axonal marker were overcome by making the lesion large enough to encompass the BDA injection site. As a result every case showed overlapping fields of BDA labeling and degeneration in area 17. In addition, Nissl staining showed no surviving neurons at the BDA injection site indicating that all BDA labeled feedback connections underwent anterograde degeneration. Furthermore, examination in the electron microscope revealed no evidence for retrograde or transneuronal degeneration of neurons in area 17 (Pubols, 1968; Fry and Cowan, 1972; Barron et al., 1973; Tanaka and Chen, 1974; Heimer and Kalil, 1978). Finally, terminal degeneration appeared to be complete 3-5 d after lesion because there were no newly degenerating terminals. Thus it is highly likely that we specifically labeled the entire contingent of feedback axons emanating from the lesion. This conclusion agrees with the results of similar experiments in rodent thalamocortical and transcallosal pathways (Porter and White, 1986; White, 1989; 
Figure 9. Schematic representation of reciprocal circuit between area 17 and LM of rat visual cortex. Feedback connections from area LM (broken lines) form synapses predominantly with pyramidal cells in area 17 ( $~ 97 \%$; filled triangles) and provide only a minor input to inhibitory interneurons ( $\sim 3 \%$; small open circles). Similarly, feedback-recipient forward-projecting neurons in area 17 (filled triangles) make short-range connections preferentially with pyramidal cells ( $\sim 97 \%$ ), many of which also make forward connections to $\mathrm{LM}$, forming a network of forward-projecting neurons strongly linked through recurrent excitatory collaterals and only weak connections to inhibitory neurons. In contrast, long-range horizontal connections of pyramidal cells in striate visual cortex provide strong input to smooth, putative GABAergic neurons ( 20\%; large open circles) (McGuire et al., 1991).

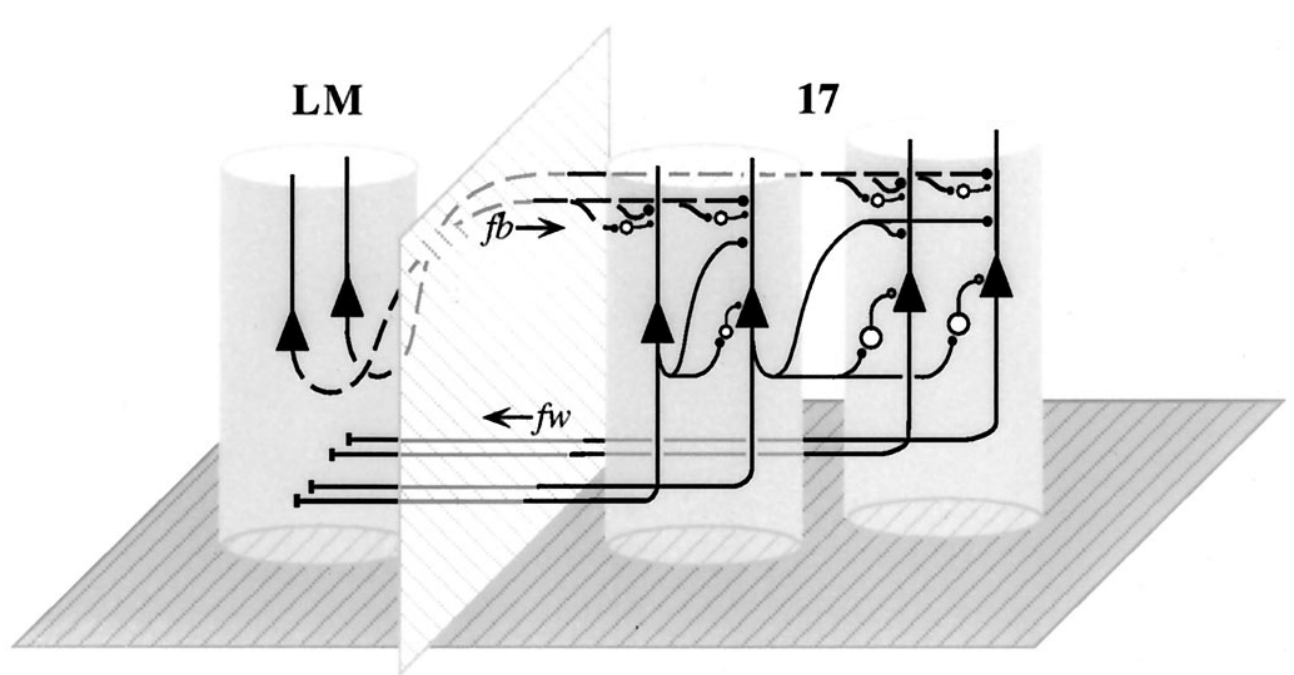

Elhanany and White, 1990; White and Czeiger, 1991; White et al., 1992; Czeiger and White, 1993).

In contrast to feedback connections, we probably labeled only a minority of forward-projecting neurons in area 17 that project to area LM. Although we have not directly compared the number of forward-projecting neurons labeled using the current technique with that obtained with other methods (Burkhalter and Charles, 1990), counts from our best cases (Jiang et al., 1993) suggested that only $\sim 40-50 \%$ of forward-projecting neurons were labeled with BDA. For reasons that are unclear, slightly fewer forwardprojecting neurons were labeled in this study $(\sim 20-30 \%)$. The finding that $11 / 63(17.5 \%)$ targets of local axon terminals of forward-projecting neurons were identified as forward-projecting neurons, therefore, should be interpreted with caution, because the actual number is likely to be higher.

\section{A circuit for intracortical facilitation via feedback pathways}

Feedback pathways synapse with forward projecting neurons

This study demonstrates that feedback inputs account for a substantial proportion of asymmetric inputs to forward-projecting neurons $(\sim 7-8 \%)$. This is similar to the strength of callosal input to callosally projecting cells ( $\sim 2-6 \%$; Porter and White, 1986). However, because area 17 receives input from several additional extrastriate areas (Coogan and Burkhalter, 1993) it is likely that convergent feedback connections account for a much greater proportion of synapses, perhaps approaching that of thalamocortical connections to layer 4 spiny stellate cells in mouse somatosensory cortex ( 20\%; Benshalom and White, 1986).

\section{Local collaterals of forward projecting cells target pyramidal neurons}

Interestingly, local axon collaterals of layer $2 / 3$ forward projecting cells in rat visual cortex preferentially contact pyramidal cells $(\sim 97-98 \%)$ and avoid GABAergic neurons in area $17(\sim 2-3 \%)$ compared with randomly selected inputs in the neuropil. Similar results have been obtained for local collaterals of callosally projecting neurons in rodent somatosensory and visual cortex (White and Czeiger, 1991; Czeiger and White, 1993). These connections, however, are different from local collaterals of forward-projecting neurons (Elhanany and White, 1990) and corticothalamic neurons (White and Keller, 1987) in mouse somatosensory cortex and layer 6 to layer 4 projections in the cat (McGuire et al., 1984) which provide $\sim 5$ - to 30 -fold stronger input to inhibitory interneurons. Although several studies in rat and cat have shown that some pathways synapse preferentially with pyramidal neurons (White and Czeiger, 1991; Czeiger and White, 1993; Keller and Asanuma, 1993; Johnson and Burkhalter, 1996), this type of connection has not yet been demonstrated in primate.

Finally, our results support the notion that short-range connections of pyramidal cells may be much less inhibitory than their long-range connections. We base this assertion on the fact that feedback pathways in the rat, which share a similar synaptic organization with short-range collaterals of forward projecting cells with (i.e., $\sim 3 \%$ input to inhibitory interneurons), provide virtually no disynaptic inhibition. In contrast, stimulation of longrange connections in upper layers of rat (Shao and Burkhalter, 1996) and cat V1 (Hirsch and Gilbert, 1991) produces strong disynaptic inhibition.

Support for the idea that long-range connections synapse with a much larger proportion of inhibitory targets is derived from monkey (McGuire et al., 1991) in which $\sim 20 \%$ of long-range axon collaterals formed synapses with putative inhibitory interneurons. Furthermore, this distinct synaptic organization of short-range and long-range circuits is consistent with anatomical evidence obtained from cat motor cortex (Keller and Asanuma, 1993). However, direct evidence that individual pyramidal cells in rat visual cortex differ in their local and long-range synaptic targets is lacking. In addition, it remains to be determined whether feedback-recipient neurons in lower layers are similar to those in upper layers.

\section{Microcircuitry of corticocortical feedback connections}

Our current conception of the organization of feedback and horizontal circuits, derived from the studies described above, is illustrated in Figure 9. The principles illustrated are are follows: (1) feedback connections provide strong excitatory input to forward projecting cells but weak excitatory input to inhibitory neurons; (2) feedback-recipient forward projecting cells make strong, excitatory short-range connections to neighboring forward projecting cells which represent the same point of the visuotopic map, but short-range input to inhibitory interneurons is weak; and (3) feedback-recipient forward projecting cells provide rela- 
tively weak excitatory input to distant forward-projecting neurons which represent dissimilar points of the visuotopic map, but strong long-range input to inhibitory neurons.

\section{Functional implications}

\section{Reciprocity}

Currently, the best understood feedback pathway is the corticogeniculate projection in the cat. Recent evidence indicates that this feedback pathway synchronizes firing in geniculate relay cells that respond to the same visual stimulus (Sillito et al., 1994). These interactions take place through a reciprocal pathway between layer 6 striate cortical neurons and relay cells in the lateral geniculate nucleus that project back to cortex (Wilson et al., 1984), although strictly speaking the connection between layer 6 corticogeniculate-projecting neurons and geniculocortical afferents has not been proven (Ahmed et al., 1994). Similarly, forwardprojecting cells in area 17 receive input from area LM and in turn send projections back to LM (this study), but forward pathways have not been shown to make direct connections with feedbackprojecting cells. Through their direct connection with forwardprojecting neurons, however, it is conceivable that corticocortical feedback pathways might play a similar role in strengthening and coordinating output from lower to higher cortical areas.

\section{Recurrent excitation via short-range collaterals}

Through a wide range of stimulation intensities, feedback inputs elicit early followed by late EPSPs in neurons of rat area 17 (Shao et al., 1996). This is very different from responses generated by activation of white matter or by long-range horizontal or forward corticocortical pathways (Shao and Burkhalter, 1996; Shao et al., 1996) in which polysynaptic excitation is evoked only by weak stimulation. We therefore suggest that feedback pathways provide preferential input to interconnected sets of forward-projecting neurons. Although similar amplification circuits involving recurrent collaterals from layer 6 to layer 4 have been postulated in the geniculocortical pathway (Ferster and Lindstrom, 1985; Katz, 1987; Douglas and Martin, 1991; Douglas et al., 1995), this circuit differs from polysynaptic feedback circuits by its high connectivity with putative inhibitory interneurons (McGuire et al., 1984; Anderson et al., 1994) and its narrow dynamic range (Hirsch, 1995).

\section{Feedback modulation of long-range horizontal connections}

It is difficult to imagine how feedback connections could modulate responses at specific visuotopic locations (Moran and Desimone, 1985; Press et al., 1994) given that feedback and long-range horizontal circuits both provide widespread, nontopographic input (cat: Gilbert, 1993; Salin and Bullier, 1995; rat: R. Knutsen and A. Burkhalter, unpublished observations). To examine this issue, Salin and Bullier (1995) proposed, on the basis of physiological observations of the cat area 18 to area 17 projection, that topographically precise feedback connections are made predominantly with excitatory neurons but that widespread feedback connections synapse mostly with inhibitory interneurons.

Their model, however, demands that feedback axons "know" when they have crossed from the visuotopically aligned domain to the nonvisuotopic domain, and that they alter their selection of postsynaptic targets accordingly. We propose instead that the distinct synaptic organization of short-range and long-range collaterals of feedback-recipient neurons may confer spatial selectivity to feedback influences via much stronger inhibitory connections formed by long-range collaterals compared with short range collaterals. This would allow feedback pathways to chose the same set of targets regardless of spatial information, and in addition allows for either facilitation or suppression via longrange horizontal connections depending on the strength at which feedback inputs are driving the surround (Shao and Burkhalter, 1996).

\section{REFERENCES}

Adams JC (1981) Heavy metal intensification of DAB-based HRP reaction product. J Histochem Cytochem 2:141-145.

Agmon A, O'Dowd DK (1992) NMDA receptor-mediated currents are prominent in the thalamocortical synaptic response before maturation of inhibition. J Neurophysiol 68:345-349.

Ahmed B, Anderson JC, Douglas RJ, Martin KAC, Nelson JC (1994) The polyneuronal innervation of spiny stellate neurons in cat visual cortex. J Comp Neurol 341:39-49.

Anderson JC, Douglas RJ, Martin KAC, Nelson JC (1994) Synaptic output of physiologically identified spiny stellate neurons in cat visual cortex. J Comp Neurol 341:16-24.

Barron KD, Means ED, Larsen E (1973) Ultrastructure of retrograde degeneration in thalamus of rat. 1. Neuronal somata and dendrites. J Neuropath Exp Neurol. 32:218-44.

Benshalom G, White EL (1986) Quantification of thalamocortical synapses with spiny stellate neurons in layer IV of mouse somatosensory cortex. J Comp Neurol 253:303-314.

Buhl EH, Schwerdtfeger W K, Germroth P, Singer W (1989) Combining retrograde tracing, intracellular injection, anterograde degeneration and electron microscopy to reveal synaptic links. J Neurosci Methods 29:241-250.

Burkhalter A (1989) Intrinsic connections of rat primary visual cortex: laminar organization of axonal projections. J Comp Neurol 279:171-186.

Burkhalter A, Charles V (1990) Organization of local axon collaterals of efferent projection neurons in rat visual cortex. J Comp Neurol 302:920-934.

Colonnier M (1981) The electron-microscopic analysis of the neuronal organization of the cerebral cortex. In: The organization of the cerebral cortex (Schmitt FO, Worden FG, Adelman G, Dennis SB, eds), pp 125-152. Cambridge: MIT.

Coogan TA, Burkhalter A (1993) Hierarchical organization of areas in rat visual cortex. J Neurosci 13:3749-3772.

Czeiger D, White EL (1993) Synapses of extrinsic and intrinsic origin made by callosal projection neurons in mouse visual cortex. J Comp Neurol 330:502-513.

Desimone R, Duncan J (1995) Neural mechanisms of selective visual attention. Annu Rev Neurosci 18:193-222.

Douglas RJ, Martin KAC (1991) A functional microcircuit for cat visual cortex. J Physiol (Lond) 440:735-769.

Douglas RJ, Koch C, Mahowald M, Martin KAC, Suarez HH (1995) Recurrent excitation in neocortical circuits. Science 269:981-985.

Elhanany E, White EL (1990) Intrinsic circuitry: synapses involving the local axon collaterals of corticocortical projection neurons in the mouse primary somatosensory cortex. J Comp Neurol 291:43-54.

Felleman DJ, Van Essen DC (1991) Distributed hierarchical processing in the primate cerebral cortex. Cereb Cortex 1:1-47.

Ferster D, Lindstrom S (1985) Synaptic excitation of neurones in area 17 of the cat by intracortical axon collaterals of cortico-geniculate cells. J Physiol (Lond) 367:233-252.

Fink RP, Heimer L (1967) Two methods for selective silver impregnation of degenerating axons and their synaptic endings in the central nervous system. Brain Res 4:369-374.

Freund TF, Gulyás AI (1991) GABAergic interneurons containing calbindin D28K or somatostatin are major targets of GABAergic basal forebrain afferents in the rat neocortex. J Comp Neurol 314:187-199.

Freund TF, Somogyi P (1983) The section-Golgi impregnation procedure. 1. Description of the method and its combination with histochemistry after intracellular iontophoresis or retrograde transport of horseradish peroxidase. Neuroscience 9:463-474.

Fry FJ, Cowan WM (1972) A study of retrograde cell degeneration in the lateral mammillary nucleus of the cat, with special reference to the role of axonal branching in the preservation of the cell. J Comp Neurol 144:1-24.

Gabbott PLA, Martin KAC, Whitteridge D (1987) Connections be- 
tween pyramidal neurons in layer 5 of cat visual cortex (area 17). J Comp Neurol 259:364-381.

Gilbert CD (1993) Circuitry, architecture, and functional dynamics of visual cortex. Cereb Cortex 3:373-386.

Haenny PE, Maunsell JHR, Schiller PH (1988) State dependent activity in monkey visual cortex. Exp Brain Res 69:245-259.

Heimer L, Kalil R (1978) Rapid transneuronal degeneration and death of cortical neurons following removal of the olfactory bulb in adult rats. J Comp Neurol 178:559-610.

Hirsch JA (1995) Synaptic integration in layer IV of the ferret striate cortex. J Physiol (Lond) 483:183-199.

Hirsch JA, Gilbert CD (1991) Synaptic physiology of horizontal connections in the cat's visual cortex. J. Neurosci. 11:1800-1809.

Jiang X-P, Johnson RR, Burkhalter A (1993) Visualization of dendritic morphology of cortical projection neurons by retrograde axonal tracing. J Neurosci Methods 50:45-60.

Johnson RR, Burkhalter A (1996) Microcircuitry of forward and feedback connections within rat visual cortex. J Comp Neurol 368:383-398.

Jones EG, Powell TPS (1970) An electron microscopic study of the laminar pattern and mode of termination of afferent fibre pathways in the somatic sensory cortex of the cat. Philos Trans R Soc Lond [Biol] 257:45-62.

Katz LC (1987) Local circuitry of identified projection neurons in cat visual cortex brain slices. J Neurosci 7:1223-1249.

Keller A, Asanuma H (1993) Synaptic relationships involving local axon collaterals of pyramidal neurons in the cat motor cortex. J Comp Neurol 336:229-242.

Kisvárday ZF, Martin KAC, TF Freund, Maglóczky Zs, Whitteridge D, Somogyi P (1986) Synaptic targets of HRP-filled layer II pyramidal cells in the cat striate cortex. Exp Brain Res 64:541-552.

Lamme VAF (1995) The neurophysiology of figure-ground segregation in primary visual cortex. J Neurosci 15:1605-1615.

Maunsell JHR, Sclar G, Nealey TA, De Priest DD (1991) Extraretinal representations in area V4 in the macaque monkey. Vis Neurosci 7:561-573.

Maunsell JHR (1995) The brain's visual world: representation of visual targets in cerebral cortex. Science 270:764-769.

McGuire BA, Hornung J-P, Gilbert CD, Wiesel TN (1984) Patterns of synaptic input to layer 4 of cat striate cortex. J Neurosci 4:3021-3033.

McGuire BA, Gilbert CD, Rivlin PK, Wiesel TN (1991) Targets of horizontal connections in Macaque primary visual cortex. J Comp Neurol 305:370-392.

Moran J, Desimone R (1985) Selective attention gates visual processing in the extrastriate cortex. Science 229:782-784.

Motter BC (1993) Focal attention produces spatially selective processing in visual cortical areas V1, V2, and V4 in the presence of competing stimuli. J Neurophysiol 70:909-919.

Peters A, Payne BR (1993) Numerical relationships between geniculocortical afferents and pyramidal cell modules in cat primary visual cortex. Cereb Cortex 3:69-78.

Peters A, Palay AL, Webster HD (1991) Fine structure of the nervous system. New York: Oxford UP.

Porter LL, White EL (1986) Synaptic connections of callosal projection neurons in the vibrissal region of mouse primary motor cortex: an electron microscopic/horseradish peroxidase study. J Comp Neurol 248:573-587.

Press WA, Knierim JJ, Van Essen DC (1994) Neuronal correlates of attention to texture patterns in macaque striate cortex. Soc Neurosci Abstr 20:838.

Pubols, Jr BH (1968) Retrograde degeneration study of somatic sensory thalamocortical connections in brain of Virginia opossum. Brain Res 7:232-251.

Salin PA, Bullier J (1995) Corticocortical connections in the visual system: Structure and function. Physiol Rev 75:107-154.

Shao Z, Burkhalter A (1996) Different balance of excitation and inhibition in forward and feedback circuits of rat visual cortex. J. Neurosci. 15:7353-7365.

Shao Z, Harding GW, Burkhalter A (1996) GABA $_{B}$ mediated inhibition in feedback circuits is weaker than in forward circuits of rat visual cortex. Soc Neurosci Abstr 22:490.

Sherman SM, Koch C (1986) The control of retinogeniculate transmission in the mammalian lateral geniculate nucleus. Exp Brain Res 63:1-20.

Sillito AM, Jones HE, Gerstein GL, West DC (1994) Feature-linked synchronization of thalamic relay cell firing induced by feedback from the visual cortex. Nature 369:479-482.

Somogyi P (1978) The study of Golgi stained cells and of experimental degeneration under the electron microscope: a direct method for the identification in the visual cortex of three successive links in a neuron chain. Neuroscience 3:167-180.

Somogyi P, Hodgson AJ (1985) Antisera to gamma-aminobutyric acid. III. Demonstration of GABA in Golgi-impregnated neurons and in conventional electron microscopic sections of cat striate cortex. J Histochem Cytochem 33:249-257.

Tanaka Jr D, Chen JYC (1974) Retrograde thalamic degeneration: observations using a modification of the Fink-Heimer silver impregnation technique. Brain Res 65:333-337.

Veenman LC, Reiner A, Honig MG (1992) Biotinylated dextran amine as an anterograde tracer for single and double labeling studies. J Neurosci Methods 41:239-254.

White EL, Keller A (1987) Intrinsic circuitry involving the local axon collaterals of corticothalamic projection cells in mouse Sm I cortex. J Comp Neurol 262:13-26.

White EL (1989) Cortical circuits: synaptic organization of the cerebral cortex. Boston: Birkhauser.

White EL, Czeiger D (1991) Synapses made by axons of callosal projection neurons in mouse somatosensory cortex: Emphasis on intrinsic connections. J Comp Neurol 303:233-244.

White EL, Czeiger D, Weinfeld E (1992) A simplified approach to retrograde/anterograde axonal labeling using combined injections of horseradish peroxidase and ibotenic acid. J Neurosci Methods 42:27-36.

Wilson JR, Friedlander MJ, Sherman SM (1984) Fine structural morphology of identified X- and Y-cells in the cat's lateral geniculate nucleus. Proc R Soc Lond [Biol] 221:411-436.

Zipser K, Lamme VAF, Schiller PH (1996) Contextual modulation in primary visual cortex. J Neurosci 16:7376-7389. 